\title{
Problematic Mukbang Watching and Its Relationship to Disordered Eating and Internet Addiction: A Pilot Study Among Emerging Adult Mukbang Watchers
}

\author{
Kagan Kircaburun $^{1}$ (D) Cemil Yurdagül ${ }^{2} \cdot$ Daria Kuss $^{1} \cdot$ Emrah Emirtekin $^{3}$ • \\ Mark D. Griffiths ${ }^{1}$
}

Published online: 21 May 2020

(C) The Author(s) 2020

\begin{abstract}
Internet technology has facilitated the use of a wide variety of different activities and applications in online contexts. One such activity is watching mukbang (i.e., watching videos of "eating broadcasts" where someone eats a large amount of food while interacting with viewers). In the present study, the relationship of problematic mukbang watching with disordered eating and internet addiction was examined. Participants were 140 emerging adults who watched mukbang at least once in the past 30 days $(66 \%$ female; $M_{a g e}=21.66, S D=1.88$, range $=19-29$ years). Structural equation modeling indicated that problematic mukbang watching was positively associated with both disordered eating and internet addiction. The present study is the first to explore the predictive role of problematic mukbang watching on adverse consequences, and suggests that mukbang watching may be problematic for a minority of emerging adults and that problematic mukbang watching warrants further examination of its impact on mental health and wellbeing.
\end{abstract}

Keywords Mukbang $\cdot$ Mukbang watching $\cdot$ Online eating shows $\cdot$ Eating disorder $\cdot$ Disordered eating $\cdot$ Internet addiction

Kagan Kircaburun

kircaburunkagan@gmail.com

Cemil Yurdagül

cemilyurdagul@gmail.com

1 Psychology Department, International Gaming Research Unit, Nottingham Trent University, 50

Shakespeare Street, Nottingham NG1 4FQ, UK

2 Faculty of Law, Ankara University, Ankara, Turkey

3 The Centre for Open and Distance Learning, Yaşar University, İzmir, Turkey 
Internet technologies allow individuals to engage in many different online activities. One such activity that has been gaining popularity among individuals is watching others eat food and socialize via eating broadcasts that are known as "mukbang" (Hong and Park 2018). Mukbang is a portmanteau term that comprises the South Korean words "eating" ("meokneun") and "broadcast" ("bangsong") (Donnar 2017). Mukbang first emerged on the South Korean online streaming channel AfreecaTV in 2008 (Hong and Park 2018) and has since spread to other places in the world after its initial introduction to western countries via an American YouTuber's video in 2015 (McCarthy 2017). At present, mukbang videos are watched by millions of viewers across the world via a variety of internet applications including different social networking sites and online streaming channels (Desai 2019).

The psychological literature on why people watch mukbang and how watching mukbang affects them is scarce. However, a small number of investigations have identified that mukbang can fulfill several psychological needs among individuals (Kircaburun et al. 2020a). A qualitative empirical study analyzed the comments of viewers of a male South Korean mukbanger (i.e., the person who eats the food in the mukbang videos) and concluded that watching mukbang alleviated viewers' real life loneliness and social isolation by making them feel emotionally connected to other viewers and the mukbanger (Choe 2019). Other content analysis studies have argued that mukbang viewers obtain a sense of relief and pleasure from listening to eating sounds such as chewing and devouring noises (Woo 2018), although these results may be culturally sensitive because there are cultural differences surrounding the eating norms and attitudes toward mukbang (Higgs 2015; Pereira et al. 2019). Nevertheless, some people appear to escape from real-life problems and negative feelings through watching mukbang (Bruno and Chung 2017), whereas mukbang provides some viewers with the vicarious pleasure of eating the desired and fantasized food so that they could avoid actually eating the food (i.e., watching mukbang as a dieting tool) (Donnar 2017).

Even though individuals may benefit from recreational mukbang watching, some vulnerable viewers may experience undesired affects from it by engaging in problematic use of the activity. According to the compensatory internet use model, individuals tend to use online activities (e.g., social networking, internet pornography, internet gaming, internet gambling) as a compensation for their unattained offline needs and those who successfully satisfy their needs using a specific online activity can sometimes become excessive users of that particular activity (Kardefelt-Winther 2014). From this perspective, obtaining aforementioned gratifications by watching mukbang (i.e., social reasons, entertainment reasons, escapist reasons, virtual eating reasons) may transform recreational mukbang watching into excessive and problematic (i.e., potentially addictive) activity for some viewers. To date, only one crosssectional study has provided any empirical evidence for problematic mukbang watching by showing that some individuals might demonstrate addiction-like symptoms associated with their mukbang watching (i.e., salience, tolerance, relapse, conflict, mood modification, withdrawal), and that the frequency of daily time spent watching mukbang was moderately related to problematic mukbang watching (Kircaburun et al. 2020b).

Individuals watch mukbang using different internet applications and platforms that facilitate interacting with videos and live streams (simultaneously and non-simultaneously) by commenting on and liking (or disliking) the mukbang content. Such tools that enable individuals to obtain different gratifications from watching mukbang increase the likelihood of promoting online addictions as well as to the specific applications that are being used to watch mukbang (Griffiths 2018; Kircaburun and Griffiths 2019). Even though the "umbrella" term "internet addiction" is fundamentally different from being addicted to an activity on the 
internet (Griffiths 1999), problematic use of activities facilitated by the internet co-exist alongside generalized internet addiction (Király et al. 2014), especially when such activities have no offline equivalent such as social networking use (Pontes and Griffiths 2014). Given that mukbang watching is mostly facilitated by social networking sites and online live streaming channels (Choe 2019), it is logical to expect that problematic mukbang watching would be associated with generalized internet addiction. This is important because internet addiction has well established adverse consequences upon individuals' mental health and physical wellbeing similar to the negative effects that arise from substance-related addictions including psychopathology, insomnia, poor sleep quality, academic failure, and experiencing family and relationship problems (Kuss and Griffiths 2012; Lam 2014; Ng and WiemerHastings 2005).

As noted above, one of the prominent gratifications obtained from mukbang watching is "vicarious eating." Watching mukbang enables viewers to satisfy their food cravings, experience the feeling of binge eating themselves, and experiencing vicarious satiation via visual and audio stimulation from the mukbangers themselves (Choe 2019; Gillespie 2019), all of which could serve as compensation for acts that an individual avoids performing in real life and/or as a fulfillment of known experiences regarding the watched act by triggering specific memories (Brennan 2017). However, given that maladaptive coping exacerbates negative emotions and mitigates positive emotions and wellbeing (Folkman and Lazarus 1988), watching mukbang as a maladaptive coping strategy to deal with real-life eating urges may also result in adverse consequences.

For instance, individuals that frequently watch mukbang may consume more than they normally would because individuals' consumption norms could easily be affected by others' consumption and mukbangers typically eat very large portions of food during a single broadcast (Spence et al. 2019). Furthermore, watching mukbang could promote problematic eating practices for those who are already experiencing different eating problems (Donnar 2017). Some newspaper stories have supported these arguments by reporting that watching mukbang was damaging teenagers' and younger viewers' eating behaviors by modeling maladaptive behavior (e.g., binge eating) and perceiving it socially acceptable (Park 2018). Consequently, given that problematic mukbang watching is more likely to be associated with more severe negative consequences of mukbang watching compared with recreational mukbang watching (Andreassen 2015), problematic mukbang watching is also more likely to relate to increased real-life problematic eating practices (i.e., disordered eating).

This is important because disordered eating (e.g., anorexia nervosa, bulimia nervosa, and binge eating disorder) is one of the notable health problems among adolescents and emerging adults, and eating disorders have become more common in recent decades especially in combination with obesity (Keski-Rahkonen and Mustelin 2016; Schmidt et al. 2016). Among a nationally representative sample of US adults, the total prevalence of lifetime eating disorders was almost $2 \%$ and emerging adults were at more risk of disordered eating compared with older age groups (Udo and Grilo 2018). A recent cross-sectional survey comprising a selfselected sample of emerging adults from different faculties of a Turkish university found that $10 \%$ of the sample was classed as at high risk for having an eating disorder (Sanlier et al. 2016). While young women make up the majority of individuals with anorexia and bulimia nervosa, men and women are nearly equally at risk for having binge eating disorder (Schmidt et al. 2016).

Having any type of eating disorder has detrimental health consequences. In a systematic review of European studies, approximately $20 \%$ of individuals with eating disorders were 
reported to experience non-suicidal self-injury because of their disordered eating (KeskiRahkonen and Mustelin 2016). Furthermore, relative to those with no history of eating disorder, those with anorexia nervosa had significantly higher odds of being categorized as underweight, whereas others with binge eating disorder had significantly increased odds of having obesity or extreme obesity (Udo and Grilo 2018). Furthermore, eating disorders have been associated with increased risk of suicide attempts and death, implying that individuals with disordered eating have an increased mortality risk (Keski-Rahkonen and Mustelin 2016).

Grounded in the assumptions of the compensatory internet use model (Kardefelt-Winther 2014) and coping style theory (Folkman and Lazarus 1988), the present study tested a structural equation model to examine the predictive role of problematic mukbang watching on disordered eating and internet addiction. While constructing the research model, the temporal precedence of the variables was decided by taking the theoretical rationale into consideration. Even though there may be bidirectional relationships among variables, the present study hypothesized that being frequently exposed to visual and audio stimuli of excessive eating (with the mukbangers' augmented demonstration of pleasure and satisfaction received from eating) would manipulate viewers' real-life practices of eating and relationship with food, which would exacerbate disordered eating.

\section{Methods}

\section{Participants, Procedure, and Ethics}

The participants comprised Turkish mukbang viewers who watched mukbang at least once in the past 30 days and completed an online survey. The survey was promoted on different online courses of a distance learning center at a private Turkish university. Participants were informed about the study at the beginning of the survey. Students gave their informed consent acknowledging that participation in the study would be voluntary and anonymous, and that they would not be rewarded for participation. A total of 952 students began the survey and 312 of them completed it (response rate $33 \%)$. Of these, 140 were mukbang viewers $\left(66 \%\right.$ female, $M_{\text {age }}=21.66, S D=1.88$, range $=$ 19-29 years). Sample power and required sample size were checked using $\mathrm{G}^{*}$ Power program with a priori analysis and the sample size $(n=140)$ was sufficient for valid results with power $>0.85, \alpha=$ 0.05 , effect size $\mathrm{f}^{2}=0.18$ because it exceeded the minimal sample size needed ( $\left.n=133\right)$ (Faul et al. 2009). Ethical approval for the study was received from the research team's university's ethics committee, and complied with the Declaration of Helsinki.

\section{Measures}

Mukbang Addiction Scale (MAS): The MAS (Kircaburun et al. 2020b) was used to assess problematic mukbang watching (e.g., "How often during the last year have you felt an urge to watch mukbang more and more?"). The initial validation study indicated mostly sound psychometric properties for unidimensional structure $\left(\chi^{2} / \mathrm{df}=2.42, \mathrm{RMSEA}=0.08\right.$ (CI 90\% $(0.03,0.13)), \mathrm{SRMR}=0.01, \mathrm{CFI}=0.99, \mathrm{GFI}=0.98)$. The scale comprises six items that assess components of six addiction-like symptoms (salience, withdrawal, mood modification, conflict, tolerance, and relapse) outlined in the biopsychosocial framework of addiction (Griffiths 2005). Items ( $1=$ never, $5=$ always $)$ were averaged to create an index of problematic mukbang watching (Cronbach's $\alpha=0.93$ ). 
Internet Addiction Scale (IAS): The IAS (Kircaburun and Griffiths 2018) was used to assess internet addiction (e.g., "How often during the last year have you tried to cut down on the use of internet without success?"). As with the MAS, the IAS comprises six items that assess components of six addiction-like symptoms (salience, withdrawal, mood modification, conflict, tolerance, relapse; Griffiths 2005). Items $(1=$ never, $5=$ always $)$ were averaged to create an index of internet addiction $(\alpha=0.93)$.

SCOFF Eating Disorders Scale: The Turkish form (Aydemir et al. 2015) of the five-item SCOFF Eating Disorders Scale (Hill et al. 2010) was used to assess risk of eating disorder symptoms including anorexia nervosa, bulimia nervosa, body dissatisfaction, and unspecified eating disorders (e.g., "Do you make yourself sick because you feel uncomfortably full?", "Do you worry that you have lost control over how much you eat?", "Do you believe yourself to be fat when others say you are too thin?"). Items $(0=$ no, $1=y e s)$ were averaged to create an index of disordered eating $(\alpha=0.71)$.

\section{Statistical Analysis}

In order to evaluate validity and reliability of the scales and to show the relationships between the variables' frequency, descriptive tests, Pearson correlations, confirmatory factor analysis (CFA), and structural equation modeling (SEM) were conducted using SPSS 23.0 and AMOS 23.0 software. For the CFA and SEM, the maximum likelihood estimation method was used. SEM was carried out by using bootstrapping method with 5000 bootstrapped samples and 95\% bias-corrected confidence intervals. According to $\mathrm{Hu}$ and Bentler (1999), thresholds for good and acceptable fit values are as follows: Root Mean Square Residuals (RMSEA) $<0.05$ is good, Standardized Root Mean Square Residuals (SRMR) $<0.05$ is good, Goodness-of-Fit Index $(\mathrm{GFI})>0.95$ is good, Comparative Fit Index $(\mathrm{CFI})>0.95$ is good, also RMSEA $<0.08$ is acceptable, SRMR $<0.08$ is acceptable, GFI $>0.90$ is acceptable, and CFI $>0.90$ is acceptable.

\section{Results}

Mean scores, standard deviations, and Pearson correlation coefficients are shown in Table 1. The analysis indicated that problematic mukbang watching was positively correlated with disordered eating $(r=0.24, p<0.01)$ and internet addiction $(r=0.26, p<0.01)$. However, the correlations were relatively low. In order to examine the effect of problematic mukbang watching on disordered eating and internet addiction, SEM was conducted (Fig. 1). Goodness of fit indices of the final model indicated adequate fit to the data $\left(\chi^{2} / \mathrm{df}=1.78, \mathrm{RMSEA}=0.07\right.$

Table 1 Mean scores, standard deviations, and Pearson correlation coefficients of the study variables

\begin{tabular}{llll}
\hline & 1 & 2 & 3 \\
\hline 1. Disordered eating & - & & - \\
2. Internet addiction & 0.09 & - & 1.43 \\
3. Problematic mukbang watching & $0.24^{* *}$ & $0.26^{* *}$ & 0.78 \\
$M$ & 0.31 & 2.91 & 1.21 \\
$S D$ & 0.31 & &
\end{tabular}




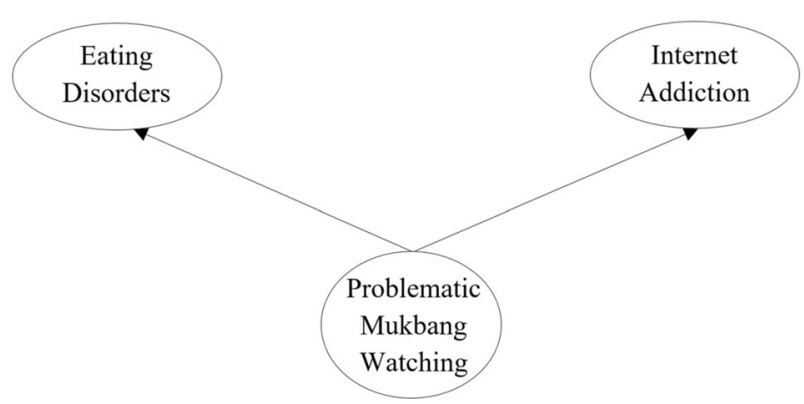

Fig. 1 Hypothesized model of the relationship of problematic mukbang watching to eating disorders and internet addiction. For clarity, items of the constructs have not been depicted in the figure. Latent variables in the model are represented with circle and observed variables with rectangles. $* p<0.05, * * p<0.01, * * * p<0.001$

CI 90\% (0.06, 0.09), $\mathrm{SRMR}=0.07, \mathrm{CFI}=0.95, \mathrm{GFI}=0.86)$. Problematic mukbang watching was positively associated with both disordered eating $(\beta=0.43, p<0.01 ; 95 \% \mathrm{CI}[0.10,0.47])$ and internet addiction $(\beta=0.29, p<0.01 ; 95 \%$ CI $[0.13,0.70])$. Problematic mukbang watching explained $18 \%$ of the variance in disordered eating and $9 \%$ in internet addiction (Fig. 2).

\section{Discussion}

With the constant developments in internet technologies, individuals fulfill a variety of needs using specific online activities. Even though the extant literature has given much attention to addictive uses of many of these activities (e.g., online gaming, online social networking, online sex, online shopping), mukbang watching has been neglected. In order to fill this gap in the scientific literature, the present preliminary study investigated the association between problematic mukbang watching and two related constructs (i.e., internet addiction and disordered

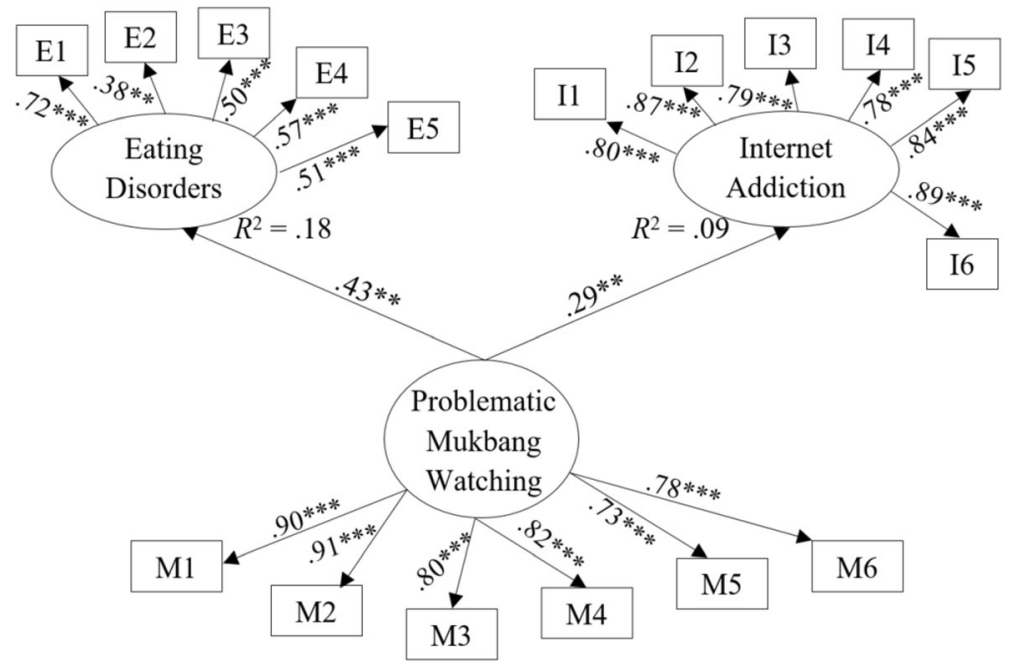

Fig. 2 Final model of the significant path coefficients demonstrating the relationship of problematic mukbang watching to eating disorders and internet addiction. Latent variables in the model are represented with circles and observed variables with rectangles. $* p<0.05$, ** $p<0.01$, *** $p<0.001$ 
eating). According to the tested structural equation model, and consistent with the theoretical assumptions of compensatory internet use model and coping style theory, problematic mukbang watching was positively associated with both disordered eating and internet addiction.

The finding regarding the exacerbating impact of problematic mukbang watching on disordered eating was consistent with the scarce literature. The act of binge eating of large portions of food demonstrated by thin and slim mukbangers has been claimed to manipulate viewers' well-established perceptions about consumption and being fit (Hong and Park 2018). Watching videos of excessive food consumption by healthy-looking individuals may facilitate viewers to perceive binge eating as a normal behavior that does not lead to negative consequences (e.g., gaining weight, health problems). This may promote binge eating disorder, which is the most common eating disorder in the world (Mitchell 2016), as well as other types of disordered eating (e.g., bulimia nervosa) as a result of maladaptive attempts to cope with binge eating (Mitchell 2016). Although the association between problematic mukbang watching and binge eating was empirically demonstrated for the first time in the online eating literature, the present finding is in line with the online sex studies reporting the exacerbating role of online pornography watching on real-life sexual hyperactivity (Böthe et al. 2019).

Another detrimental impact of dealing with the real-life eating urges by watching others eat food may be that it negatively affects an individual's relationship with real-life eating. Previous studies from the pornography use literature have demonstrated that excessive use of online porn in both adolescence and adulthood leads to real-life sexual dysfunctions including low sexual desire and increased erectile dysfunctions (Zimbardo et al. 2016). Similarly, unrealistic visual and audio stimuli demonstrated in mukbang videos (augmented acts of pleasure and satisfaction shown by the mukbangers while eating (Gillespie 2019)) can lead to diminished pleasure received from actual eating, and in turn, promote disordered eating (e.g., anorexia nervosa) through the displacement of real eating with virtual eating. Consequently, problematic mukbang watching could potentially facilitate different eating disorders among different viewers.

Another important finding of the present study was that problematic mukbang watching was positively associated with internet addiction. This result is consistent with the existing empirical literature suggesting that internet addiction is an umbrella term for problematic use of specific types of activities facilitated by the internet including online gaming addiction, online shopping addiction, online social networking addiction, and online pornography addiction (Montag et al. 2015). Montag et al. (2015) argued that the most consistent and strongest relationship with internet addiction was social networking addiction, because social networking use has no offline equivalent (i.e., it is a behavior that can only be carried out online). Some individuals first air their video on AfreecaTV and then upload it to social media, while others upload and stream directly on social media (Gillespie 2019). Thus, it is not surprising that problematic mukbang watching significantly contributed to elevated internet addiction among the participants.

The present study has some limitations that should be taken into account when interpreting the results. To begin with, the utilization of cross-sectional design prevents conclusions with respect to the causal associations among, and temporal ordering of, the variables. Therefore, further studies are needed to confirm the results illustrated in the present study using longitudinal designs. Another limitation was that the study comprised a very small number of Turkish emerging adults who watched mukbang in the past month. However, this is not a common behavior in Turkey so numbers were expected to be low. This limits the generalizability of the 
present results (both inside and outside of Turkey). Future studies should attempt to replicate the findings here recruiting higher numbers of participants from different age groups and cultures. Third, the data were collected using self-report online survey in a self-selected sample, which is susceptible to well-known biases and limitations including social desirability and lack of introspection. Consequently, future studies should examine the relationships found in this study using more in-depth data collection tools and methods. Also, using a similar selfreport format to test constructs simultaneously promotes the possibility that shared method variance and response bias might account for the found relationships between the variables.

Despite its limitations, to the best of authors' knowledge, the present study is the first to report that problematic mukbang watching might be associated with negative consequences. More specifically, the results demonstrated that problematic mukbang watching was positively associated with both disordered eating and internet addiction. Spending excessive time watching mukbang and being preoccupied with watching mukbang to facilitate mood modification could lead to the onset, development, and maintenance of different eating disorders and generalized internet addiction among a small minority of individuals. It appears that being visually exposed to others' eating promotes unhealthy eating practices and potentially addictive technology use. Health professionals and clinicians may take mukbang watching into account when developing effective strategies to prevent disordered eating and internet addiction, although further studies are needed.

\section{Compliance with ethical standards}

Conflict of interest The authors report no conflict of interest.

Ethical approval Ethical approval for the study was received from the research team's university's ethics committee, and complied with the Declaration of Helsinki.

Statement of informed consent Students gave their informed consent acknowledging that participation in the study would be voluntary and anonymous, and that they would not be rewarded for participation.

Open Access This article is licensed under a Creative Commons Attribution 4.0 International License, which permits use, sharing, adaptation, distribution and reproduction in any medium or format, as long as you give appropriate credit to the original author(s) and the source, provide a link to the Creative Commons licence, and indicate if changes were made. The images or other third party material in this article are included in the article's Creative Commons licence, unless indicated otherwise in a credit line to the material. If material is not included in the article's Creative Commons licence and your intended use is not permitted by statutory regulation or exceeds the permitted use, you will need to obtain permission directly from the copyright holder. To view a copy of this licence, visit http://creativecommons.org/licenses/by/4.0/.

\section{References}

Andreassen, C. S. (2015). Online social network site addiction: A comprehensive review. Current Addiction Reports, 2, 175-184.

Aydemir, Ö., Köksal, B., Sapmaz, S. Y., \& Yüceyar, H. (2015). Reliability and validity of Turkish form of SCOFF Eating Disorders Scale. Anatolian Journal of Psychiatry, 16, 31-35.

Bőthe, B., Tóth-Király, I., Potenza, M. N., Griffiths, M. D., Orosz, G., \& Demetrovics, Z. (2019). Revisiting the role of impulsivity and compulsivity in problematic sexual behaviors. Journal of Sex Research, 56, 166-179.

Brennan, J. (2017). Public-sex: Viewer discourse on Deerborn's 'homemade' gay porn. Psychology \& Sexuality, $8,55-68$. 
Bruno, A. L., \& Chung, S. (2017). Mŏkpang: Pay me and I'll show you how much I can eat for your pleasure. Journal of Japanese and Korean Cinema, 9, 155-171.

Choe, H. (2019). Eating together multimodally: Collaborative eating in mukbang, a Korean livestream of eating. Language in Society, 48, 171-208.

Desai, K. (2019). These binge-eating stars get paid to gorge on camera. Times of India, October 9. Retrieved May 19, 2020, from https://timesofindia.indiatimes.com/india/these-binge-eating-stars-get-paid-to-gorge-oncamera/articleshow/71500011.cms.

Donnar, G. (2017). 'Food porn' or intimate sociality: Committed celebrity and cultural performances of overeating in meokbang. Celebrity Studies, 8, 122-127.

Faul, F., Erdfelder, E., Buchner, A., \& Lang, A. G. (2009). Statistical power analyses using G* power 3.1: Tests for correlation and regression analyses. Behavior Research Methods, 41, 1149-1160.

Folkman, S., \& Lazarus, R. S. (1988). Coping as a mediator of emotion. Journal of Personality and Social Psychology, 54, 466-475.

Gillespie, S. L. (2019). Watching women eat: A critique of magical eating and mukbang videos. Doctoral dissertation, University of Nevada, Reno, USA. Retrieved 16 October, 2019, from: https://scholarworks.unr. edu/bitstream/handle/11714/6027/Gillespie_unr_0139M_12971.pdf?sequence $=1$.

Griffiths, M. D. (1999). Internet addiction: Internet fuels other addictions. Student British Medical Journal, 7 , $428-429$.

Griffiths, M. D. (2005). A 'components' model of addiction within a biopsychosocial framework. Journal of Substance Use, 10, 191-197.

Griffiths, M. D. (2018). Adolescent social networking: How do social media operators facilitate habitual use? Education and Health, 36, 66-69.

Higgs, S. (2015). Social norms and their influence on eating behaviours. Appetite, 86, 38-44.

Hill, L. S., Reid, F., Morgan, J. F., \& Lacey, J. H. (2010). SCOFF, the development of an eating disorder screening questionnaire. International Journal of Eating Disorders, 43, 344-351.

Hong, S., \& Park, S. (2018). Internet mukbang (foodcasting) in South Korea. In I. Eleá \& L. Mikos (Eds.), Young and creative: digital technologies empowering children in everyday life (pp. 111-125). Göteborg: Nordicom.

Hu, L. T., \& Bentler, P. M. (1999). Cutoff criteria for fit indexes in covariance structural analysis: Conventional criteria versus new alternatives. Structural Equation Modelling, 6, 1-55.

Kardefelt-Winther, D. (2014). A conceptual and methodological critique of internet addiction research: Towards a model of compensatory internet use. Computers in Human Behavior, 31, 351-354.

Keski-Rahkonen, A., \& Mustelin, L. (2016). Epidemiology of eating disorders in Europe: Prevalence, incidence, comorbidity, course, consequences, and risk factors. Current Opinion in Psychiatry, 29, 340-345.

Király, O., Griffiths, M. D., Urbán, R., Farkas, J., Kökönyei, G., Elekes, Z., Tamás, D., \& Demetrovics, Z. (2014). Problematic internet use and problematic online gaming are not the same: Findings from a large nationally representative adolescent sample. Cyberpsychology, Behavior and Social Networking, 17, 749754.

Kircaburun, K., \& Griffiths, M. D. (2018). The dark side of internet: Preliminary evidence for the associations of dark personality traits with specific online activities and problematic internet use. Journal of Behavioral Addictions, 7, 993-1003.

Kircaburun, K., \& Griffiths, M. D. (2019). Problematic Instagram use: The role of perceived feeling of presence and escapism. International Journal of Mental Health and Addiction, 17, 909-921.

Kircaburun, K., Harris, A., Calado, F., \& Griffiths, M. D. (2020a). The psychology of mukbang watching: A scoping review of the academic and non-academic literature. International Journal of Mental Health and Addiction. https://doi.org/10.1007/s11469-019-00211-0.

Kircaburun, K., Stavropoulos, V., Harris, A., Calado, F., Emirtekin, E., \& Griffiths, M. D. (2020b). Development and validation of the Mukbang addiction scale. International Journal of Mental Health and Addiction. https://doi.org/10.1007/s11469-019-00210-1.

Kuss, D. J., \& Griffiths, M. D. (2012). Internet and gaming addiction: A systematic literature review of neuroimaging studies. Brain Sciences, 2, 347-374.

Lam, L. T. (2014). Internet gaming addiction, problematic use of the internet, and sleep problems: A systematic review. Current Psychiatry Reports, 16, e444.

McCarthy, A. (2017). This Korean food phenomenon is changing the internet. Eater, April 19. Retrieved May 19, 2020, from https://www.eater.com/2017/4/19/15349568/mukbang-videos-korean-youtube.

Mitchell, J. E. (2016). Medical comorbidity and medical complications associated with binge-eating disorder. International Journal of Eating Disorders, 49, 319-323.

Montag, C., Bey, K., Sha, P., Li, M., Chen, Y. F., Liu, W. Y., Zhu, Y. K., Li, C. B., Markett, S., Keiper, J., \& Reuter, M. (2015). Is it meaningful to distinguish between generalized and specific internet addiction? 
Evidence from a cross-cultural study from Germany, Sweden, Taiwan and China. Asia-Pacific Psychiatry, 7, 20-26.

Ng, B. D., \& Wiemer-Hastings, P. (2005). Addiction to the internet and online gaming. Cyberpsychology \& Behavior, 8, 110-113.

Park, K. (2018). South Korea to clamp down on binge-eating trend amid obesity fears. The Daily Telegraph, October 25. Retrieved May 19, 2020, from https://www.telegraph.co.uk/news/2018/10/25/south-koreaclamp-binge-eating-trend-amid-obesity-fears/.

Pereira, B., Sung, B., \& Lee, S. (2019). I like watching other people eat: A cross-cultural analysis of the antecedents of attitudes towards Mukbang. Australasian Marketing Journal, 27, 78-90.

Pontes, H. M., \& Griffiths, M. D. (2014). Internet addiction disorder and internet gaming disorder are not the same. Journal of Addiction Research \& Therapy, 5, e124.

Sanlier, N., Yassibas, E., Bilici, S., Sahin, G., \& Celik, B. (2016). Does the rise in eating disorders lead to increasing risk of orthorexia nervosa? Correlations with gender, education, and body mass index. Ecology of Food and Nutrition, 55, 266-278.

Schmidt, U., Adan, R., Böhm, I., Campbell, I. C., Dingemans, A., Ehrlich, S., Elzakkers, I., Favaro, A., Giel, K., Harrison, A., \& Himmerich, H. (2016). Eating disorders: The big issue. The Lancet Psychiatry, 3, 313-315.

Spence, C., Mancini, M., \& Huisman, G. (2019). Digital commensality: Eating and drinking in the company of technology. Frontiers in Psychology, 10, 2252.

Udo, T., \& Grilo, C. M. (2018). Prevalence and correlates of DSM-5-defined eating disorders in a nationally representative sample of US adults. Biological Psychiatry, 84, 345-354.

Woo, S. (2018). Mukbang is changing digital communications. Anthropology Newsletter, 59, 90-94.

Zimbardo, P., Wilson, G., \& Coulombe, N. (2016). How porn is messing with your manhood. Skeptic, 21, 2227.

Publisher's Note Springer Nature remains neutral with regard to jurisdictional claims in published maps and institutional affiliations. 